\title{
Reviews
}

\section{Role of free radicals and antioxidants in the pathogenesis of the inflammatory periodontal diseases}

\author{
Iain L C Chapple
}

\section{Introduction}

The human inflammatory periodontal diseases are amongst the most common of chronic diseases to affect adults. In the UK, $69 \%$ of adults have early signs of disease and only $5 \%$ are completely free from clinical signs of inflammation. ${ }^{1}$ The periodontal complex comprises alveolar bone, periodontal ligament, root cementum, and the overlying gingival (gum) tissues (fig 1). Gingivitis may be defined as "an inflammatory lesion, mediated by hostparasite interactions, that is confined to the gingival tissues". The major cause of gingivitis is an accumulation of microbial plaque in and around the dento-gingival complex, which, when removed, results in complete resolution of the inflammatory lesion. ${ }^{2}$ Periodontitis is regarded as "an inflammatory lesion, mediated by complex host-parasite interactions, that leads to the loss of connective tissue attachment to root surface cementum and adjacent alveolar bone". There are many forms of periodontitis ${ }^{3}$ and the changes associated with periodontitis are irreversible, resulting in tooth loss and substantial morbidity in medically compromised patients, where a focus of infection and subsequent bacteraemia may present a major risk.

The mouth possesses a unique hard/soft tissue barrier, that separates the internal systems from the external environment. The barrier (fig 1 ) is called the junctional epithelium and is permeable to external (bacterial) material passing into the adjacent connective tissues and blood stream, and to products of internal defence systems (leucocytes, complement, antibodies, pro-inflammatory cytokines, etc.) passing outwards. To assist this vulnerable barrier in protecting the underlying host tissues from damage by products of bacterial plaque, a fluid, gingival crevicular fluid (GCF), is produced from beneath the gingival margin. In health, GCF is a serum transudate containing all components of serum and also polymorphonuclear leucocyte cells, but during disease many products of the host-parasite conflict enter the fluid, which becomes a true exudate. GCF may be collected non-invasively on paper strips $^{4}$ (fig 2), providing an ideal medium in which to study the complex bacterial-host interactions (fig 3) that characterise other similar inflammatory disorders.

Substantial data are available in the literature on the role of reactive oxygen species (ROS) and antioxidants in disorders such as the inflammatory lung diseases and in chronic immune mediated conditions such as rheumatoid arthritis. However, remarkably little information is available on the periodontal diseases, which show many of the pathological features of other chronic inflammatory diseases. The periodontal tissues also provide an ideal medium within which to study mechanisms of ROS mediated tissue damage and of antioxidant defence in response to bacterial colonisation, through the non-invasive collection of GCF. This paper, therefore, attempts to review current knowledge of free radical damage and antioxidant defence systems in inflammatory diseases, and to use the inflammatory periodontal diseases as a focus for discussion. Emphasis is placed upon the presence of low molecular weight thiols such as reduced glutathione (GSH) and cysteine in fluids that bathe vulnerable epithelial surfaces, and it is postulated that new therapeutic pathways may be found by using cysteine and GSH preserving drugs-for example, $\mathrm{N}$-acetylcysteine, or indeed, inhibitors of the nuclear transcription factor NF- $\mathrm{kB}$.

\section{Inflammatory cells and reactive oxygen species}

There is good evidence arising from studies of defective neutrophil function in ChediakHigashi syndrome, ${ }^{5}$ acatalasia, ${ }^{6}$ Job's syndrome, ${ }^{5}$ and chronic granulomatous disease, ${ }^{7}$ where profound tissue inflammation can lead to periodontal destruction, that the polymorphonuclear leucocyte has a protective role in the periodontal environment. However, evidence is emerging from several studies ${ }^{8-10}$ that in early onset forms of periodontitis, polymorphonuclear leucocytes are functionally activated and exhibit increased free radical production as measured by luminol dependent chemiluminescence. Indeed, peripheral blood monocytes from patients with periodontitis demonstrate higher prostaglandin $\mathrm{E}_{2}$ production upon stimulation than those from patients 


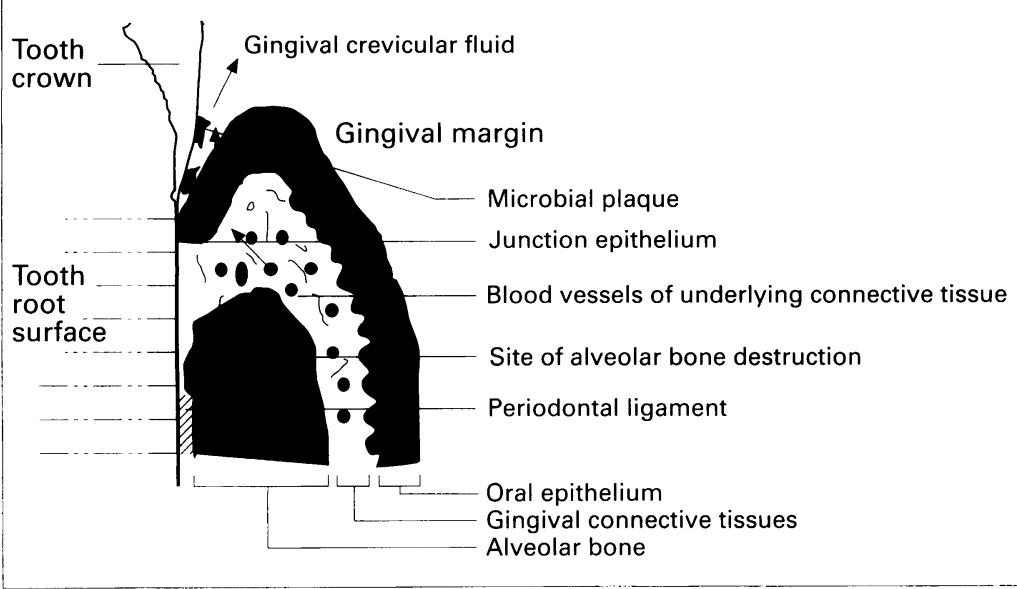

Figure 1 Longitudinal section through a tooth and adjacent periodontal tissues.

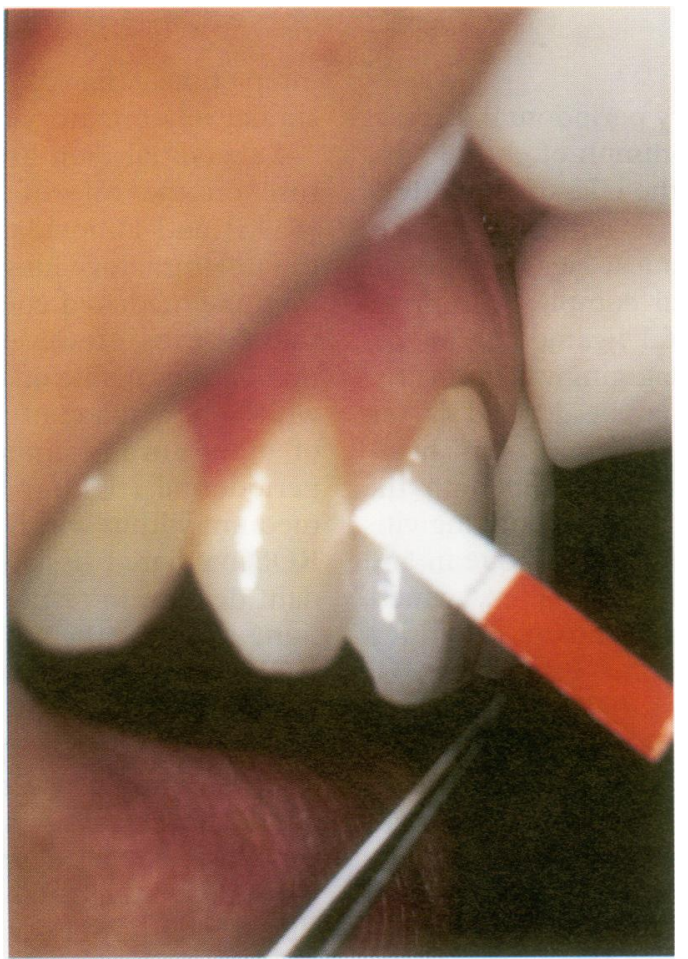

Figure 2 Colour slide illustrating the non-invasive collection of gingival crevicular fluid.

without the disease, indicating priming of peripheral leucocytes by the omnipresent lipopolysaccharide of Gram negative pathogens, or an underlying immune based susceptibility to the disease. ${ }^{11}$ There seems, therefore, to be a delicate balance between inflammatory and immune cell hypofunction, where unchecked pathogens cause direct tissue damage, and hyperfunction, where host defence cell products elaborated in an effort to eliminate pathogens inadvertently cause substantial collateral host tissue damage (fig 3). Such products can be categorised broadly into enzymatic mechanisms and those derived from the oxidative burst.

Enzyme based mechanisms arise following degranulation and include enzymes, such as collagenase, hyaluronidase, elastase, etc., which are released in an attempt to destroy bacteria, but also cause damage to host tissue as a side effect of their actions.

The oxygen dependent pathways of phagocyte function give rise to the production of free radical species, which may be defined as any species capable of independent existence that contains one or more unpaired electrons. ${ }^{12}$ In recent years the term reactive oxygen species has been adopted to include molecules such as hydrogen peroxide $\left(\mathrm{H}_{2} \mathrm{O}_{2}\right)$, hypochlorous acid $(\mathrm{HOCl})$ and singlet oxygen $\left({ }^{1} \mathrm{O}_{2}\right)$, which, while not radicals in nature, are capable of radical formation in the extra- and intracellular environments. ${ }^{13}$ Reactive oxygen species cause tissue damage by a variety of different mechanisms:

- lipid peroxidation (through activation of cyclooxygenases and lipoxygenases);

- DNA damage (base hydroxylations and strand breaks);

- protein damage, including gingival hyaluronic acid and proteoglycans ${ }^{14}$;

- oxidation of important enzymes-for example, anti-proteases such as $\alpha$-1-antitrypsin ${ }^{15}$; and

- stimulation of pro-inflammatory cytokine release by monocytes and macrophages, by depleting intracellular thiol compounds and activating nuclear factor $\kappa \mathrm{B}(\mathrm{NF}-\mathrm{\kappa B}) .^{16}$

Most reactive oxygen species have extremely short half-lives $\left(10^{-9}\right.$ to $10^{-6}$ seconds $),{ }^{17}$ but they can cause substantial tissue damage by initiating free radical chain reactions. There are exogenous sources of ROS such as cigarette smoke and ionising radiation. Endogenous production is, however, more pertinent to the pathogenesis of periodontal disease and arises either accidentally due to leakage of electrons from their carriers within the respiratory chain of mitochondria passing directly onto oxygen, ${ }^{18}{ }^{19}$ or functionally through the generation of oxygen radicals by phagocytes (fig 4). The latter process is thought to be implicated in the destruction of the connective tissues of the periodontium

THE SUPEROXIDE ANION

Superoxide $\left(\mathrm{O}_{2}{ }^{-}\right)$is formed chemically by the addition of an extra electron to oxygen (where - signifies an unpaired electron):

$$
\mathrm{O}_{2}+\mathrm{e}-\longrightarrow \mathrm{O}_{2}{ }^{*}
$$

Polymorphonuclear leucocytes and macrophages (and to a lesser extent eosinophils, lymphocytes and fibroblasts) are examples of cells that produce superoxide as an antibacterial agent. $^{2122}$ Production in the polymorphonuclear leucocyte is the result of the so-called membrane bound reduced nicotinamide adenine dinucleotide phosphate (NADPH) oxidase shunt (or hexose monophosphate shunt). This shunt fails to work in chronic granulomatous disease (CGD), ${ }^{21}$ which is why neutrophils from patients with CGD can engulf opsonised bacteria, but are unable to kill certain strains which are subsequently released in a viable state.

$$
\begin{aligned}
& 2 \mathrm{NADPH}+2 \mathrm{O}_{2} \underset{\frac{\text { hexose monophosphate shunt }}{\text { or NADPH oxidase shunt }}}{ } \\
& 2 \mathrm{NADP}+2 \mathrm{H}^{+}+2 \mathrm{O}_{2}^{\cdot}
\end{aligned}
$$

Superoxide is regarded as a weakly reactive radical, relative to the hydroxyl radical, but can nevertheless attack a number of biological tar- 


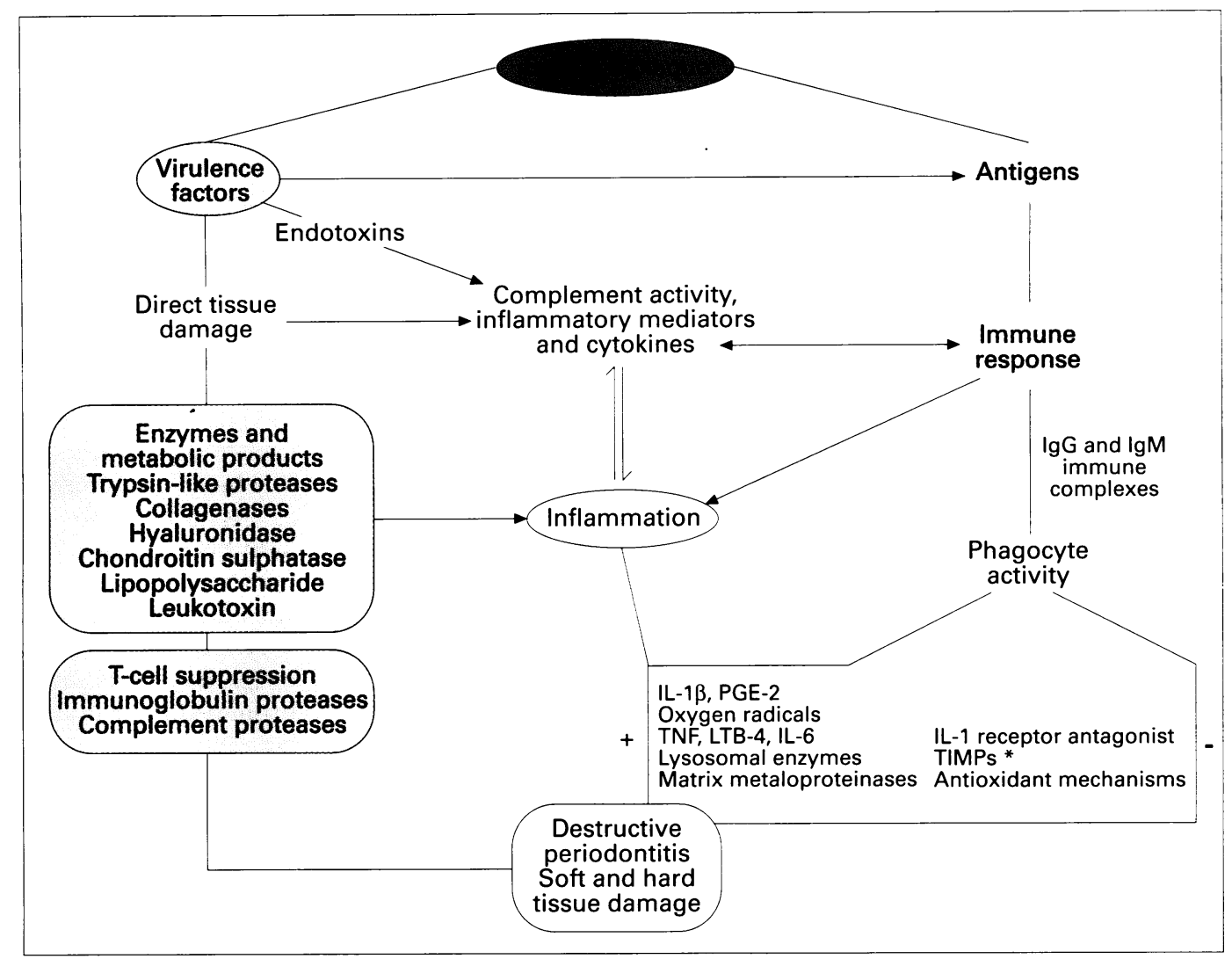

Figure 3 Some examples of the complex host-parasite interactions that may contribute to periodontal tissue destruction. $T I M P=$ tissue inhibitor or matrix metalloproteinases; LTB4 = leukotriene B4; PGE-2 = prostaglandin E-2.

gets of periodontal relevance. It can also spontaneously dismutate in aqueous solution to form hydrogen peroxide and singlet oxygen, which can in turn cause cell damage. Superoxide has also recently been localised at the ruffled border space of osteoclasts, implying a role in bone matrix degradation at the osteoclast-bone interface. ${ }^{23}$

$$
\mathrm{O}_{2}{ }^{\cdot-}+\mathrm{O}_{2}{ }^{\cdot-}+2 \mathrm{H}^{+} \longrightarrow{ }^{1} \mathrm{O}_{2}+\mathrm{H}_{2} \mathrm{O}_{2}
$$

Superoxide can also be converted to the more potent hydroxyl radical by reaction with hydrogen peroxide, a complex procedure, catalysed by metal ions (iron-catalysed HaberWeiss reaction).

$$
\mathrm{O}_{2}{ }^{\cdot-}+\mathrm{H}_{2} \mathrm{O}_{2} \stackrel{\mathrm{Fe}^{2 *} \text { or Cü*ions }}{\longrightarrow} \mathrm{OH}+\mathrm{OH}^{-}+\mathrm{O}_{2}
$$

Superoxide is either removed from tissues by superoxide dismutase (SOD), a process that can also be catalysed to form oxygen and hydrogen peroxide, or by spontaneous dismutation to hydrogen peroxide. SOD is a vital enzyme based antioxidant defence mechanism largely found intracellularly, ${ }^{24}$ but may also be present in very small amounts in the extracellular environment. The hydrogen peroxide that forms through its action is then removed by a second enzyme called catalase, which is again largely intracellular, and found only in small amounts, if at all, extracellularly. Red blood cells contain large amounts of catalase and are believed to act as a sink for hydrogen peroxide and superoxide removal.

$$
\begin{gathered}
2 \mathrm{O}_{2}{ }^{--}+2 \mathrm{H}^{+} \stackrel{\text { soD }}{\longrightarrow} \mathrm{H}_{2} \mathrm{O}_{2}+\mathrm{O}_{2} \\
2 \mathrm{H}_{2} \mathrm{O}_{2} \stackrel{\text { catalase }}{\longrightarrow} 2 \mathrm{H}_{2} \mathrm{O}+\mathrm{O}_{2}
\end{gathered}
$$

The role of catalase in the extracellular environment is performed by a very important enzyme called glutathione peroxidase (GSH$\mathrm{Px}$ ), which is largely selenium dependent and reduces $\mathrm{H}_{2} \mathrm{O}_{2}$ whilst oxidising reduced glutathione (GSH) to its oxidised form (GSSG).

$$
2 \mathrm{GSH}+\mathrm{H}_{2} \mathrm{O}_{2} \stackrel{\text { GSH-Px }}{\longrightarrow} \mathrm{GSSG}+2 \mathrm{H}_{2} \mathrm{O}
$$

THE HYDROXYL RADICAL

The hydroxyl radical is the most reactive radical known to man and interacts with most biological molecules. It can be formed from superoxide through the iron catalysed HaberWeiss reaction, or from hydrogen peroxide through another transition metal dependent reaction called the Fenton reaction. This reaction is largely dependent upon $\mathrm{Fe}^{2+}$ and $\mathrm{Cu}^{2+}$ ions, ${ }^{25}$ and thus proteins that sequester iron or copper (for example, albumin, caeruloplasmin, haptoglobin, lactoferrin, and transferrin) are extremely important antioxidants. ${ }^{26-30}$

$$
\mathrm{Fe}^{2+}+\mathrm{H}_{2} \mathrm{O}_{2} \longrightarrow \mathrm{Fe}^{3+}+{ }^{\circ} \mathrm{OH}+\mathrm{OH}^{-}
$$

The hydroxyl radical can stimulate a classic free radical chain reaction known as lipid peroxidation. When the hydroxyl radical is generated close to membrane phospholipids, it attacks the lipid side chains to form radical intermediates called peroxyl radicals $\left(\mathrm{RO}_{2}{ }^{\circ}\right)$, hydrogen peroxide and lipid hydroperoxides. Arachadonic acid is a preferential target for the hydroxyl radical. The accumulation of hydroperoxides can disrupt membrane function ${ }^{12}$ and the hydroperoxides can decompose to form cytotoxic aldehydes. ${ }^{31}$ End products of such lipid peroxidations include a unique class 
Polymorphonuclear leucocyte activation

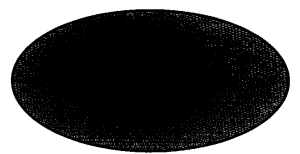

Respiratory burst

$\stackrel{\mathrm{O}_{2}^{-}}{-}$

Superoxide anion

Formed by NADPH oxidase

(Hexose-monophosphate) shunt

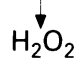

Formed via spontaneous dismutation or via action of intracellular superoxide dismutase

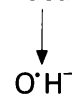

Hydroxyl radical formation via Fenton reactions with $\mathrm{Fe}^{2+}$ or $\mathrm{Cu}^{2+}$

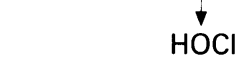

Hypochlorous acid formation via action of myeloperoxidase
Figure 4 Production of reactive oxygen species following activation of polymorphonuclear leucocytes.

of prostaglandin $\mathrm{F}_{2}$-like compounds, ${ }^{32}{ }^{33}$ a prostanoid involved in lymphokine production, vasodilation, and osteoclastic resorption of bone. Lipid peroxidation end products also cause a dysfunction of $\mathrm{Ca}^{2+}$-ATPase ${ }^{34}$ and may cause opening of intracellular pores, ${ }^{34}$ both of which lead to an accumulation of intracellular calcium. The $\mathrm{Ca}^{2+}$ build up causes activation of $\mathrm{Ca}^{2+}$ dependent enzymes (proteases and phospholipase), which in turn cause cell damage. In addition, protein damage can arise via radical mediated inactivation of membrane bound receptors and enzymes ${ }^{36}$ and damage to glycoproteins. $^{37}$

Other mechanisms of hydroxyl mediated tissue damage involve DNA strand breaks ${ }^{38}$ and base hydroxylations, ${ }^{39} 40$ leading to ATP depletion and gene mutations which can in turn result in malignant transformation or cell death. ${ }^{41}$

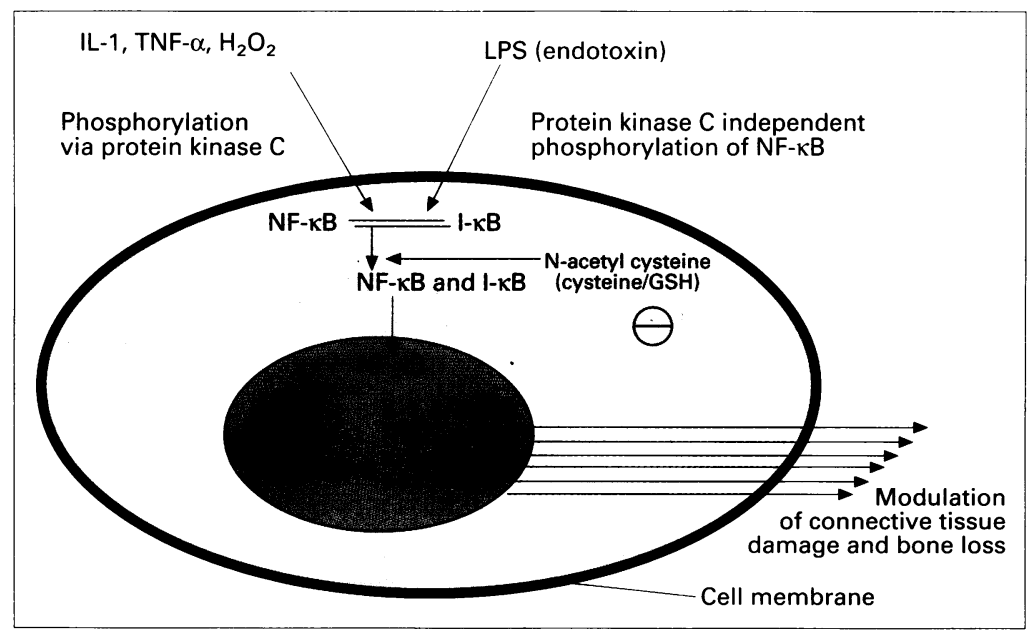

Figure 5 Diagrammatic representation of some stimulants and inhibitors of $N F-\kappa B$ mediated pro-inflammatory cytokine $m R N A$ transcription. LPS = lipopolysaccharide.
Mechanisms of preventing hydroxyl radical induced tissue damage include the binding of transition metal ions by the "preventative antioxidants" albumin, caeruloplasmin, haptoglobin, lactoferrin, and transferrin. Scavengers of the hydroxyl radical include vitamin C, uric acid ${ }^{42}$ and thiols, such as reduced glutathione ${ }^{20}$ and cysteine.

HYDROGEN PEROXIDE

Hydrogen peroxide can be produced by periodontal bacteria, by phagocytes from the NADPH oxidase shunt and also after dismutation of superoxide. While only a weak oxidant, it is has high potential to produce damage due to its ability to diffuse freely across cell membranes ${ }^{43}$ and undergo Fenton reactions with transition metals, thereby giving rise to site directed or site specific generation of ${ }^{\circ} \mathrm{OH} .{ }^{44}$ It has been proposed that hydrogen peroxide may act as a metabolic signal by oxidising protein thiol groups and triggering intracellular events. ${ }^{43}$ An example would be the oxidation of an important nuclear regulatory protein $\mathrm{NF \kappa B}$, a process thought to be responsible for the expression of HIV genes. ${ }^{45}$

The activity of hydrogen peroxide on NF- $\mathrm{KB}$ is also responsible for the transcription of several pro-inflammatory cytokines ${ }^{46}$ of importance to periodontal disease pathogenesis, including interleukin-2 (IL-2), IL-6, IL-8, $\beta$-interferon, and tumour necrosis factor $\alpha$ (TNF $\alpha$ ). ${ }^{47} \mathrm{NF}-\kappa \mathrm{B}$ activation (fig 5 ) can also be caused by bacterial endotoxins, IL- 1 and TNF $\alpha{ }^{48-51}$ The process is rapid, as NF- $\kappa \mathrm{B}$ exists in the cytoplasm of most inflammatory cells, in a complex with an inhibited form (I- $\kappa \mathrm{B})$. Cytokines such as TNF- $\alpha$ and IL-1 are able to activate $\mathrm{NF}-\kappa \mathrm{B}$ via protein kinase $\mathrm{C}$ and other kinases, which phosphorylate the $\mathrm{I}-\kappa \mathrm{B}$ part of the cytoplasmic complex, thereby releasing free $\mathrm{NF}-\kappa \mathrm{B}$ rapidly and without the need for lengthy protein synthesis. The free NF- $\kappa B$ diffuses from the cytoplasm, across the nuclear membrane and binds to DNA, stimulating the transcription of mRNA for the various proinflammatory cytokines. Recently, it has been shown that bacterial lipopolysaccharide (LPS/endotoxin) can also activate macrophage NF- $\mathrm{KB}$ and subsequent cytokine transcription in a protein kinase $\mathrm{C}$ independent manner. ${ }^{51}$ As IL-1 and TNF $\alpha$ positively regulate their own production through the $\mathrm{NF}-\kappa \mathrm{B}$ system, it is possible that the additive effects of endotoxin mediated cytokine production and that arising from the respiratory burst of polymorphonuclear leucocytes in response to the same organisms, could lead to substantial periodontal inflammation and subsequent tissue destruction

Hydrogen peroxide is removed from cells by the action of antioxidant enzymes-for example, catalase, selenium dependent glutathione peroxidase and some other peroxidases. ${ }^{52}$

\section{HYPOCHLOROUS ACID}

Hypochlorous acid is a powerful antibacterial agent ${ }^{53}$ and is also capable of causing oxidation of plasma membrane thiol $(\mathrm{SH})$ groups and disruption of certain protein functions, ${ }^{54}$ even 
Table 1 Important extracellular antioxidants, their modes of action, solubility, and locations

\begin{tabular}{|c|c|c|c|}
\hline Antioxidant & Mode of action & Solubility & Location \\
\hline Ascorbic acid (vitamin C) & $\begin{array}{l}\text { Chain breaking (scavenging) } \\
\text { Preventative (binds metal ions) } \\
\text { Regenerates } \alpha \text {-tocopherol }\end{array}$ & Water soluble & Plasma, saliva, GCF, CSF, synovial fluid \\
\hline Alpha-tocopherol (vitamin E) & Chain breaking (scavenging) & Lipid soluble & Plasma, saliva, GCF \\
\hline Carotenoids (vitamin A) & Chain breaking (scavenging) & Lipid soluble & Plasma \\
\hline Albumin & $\begin{array}{l}\text { Preventative (binds metal ions) } \\
\text { Binds bilirubin also } \\
\text { Chain breaking (scavenging) }\end{array}$ & Water soluble & Plasma, saliva, GCF \\
\hline Bilirubin & Chain breaking (binds to and protects albumin) & Lipid soluble & Plasma \\
\hline Caeruloplasmin & Preventative (binds metal ions) & Water soluble & Plasma, saliva, GCF \\
\hline Haptoglobin & Preventative (binds metal ions) & Water soluble & Plasma, GCF \\
\hline Transferrin & Preventative (binds $\mathrm{Fe}^{2+}$ ions) & Water soluble & Plasma, saliva, GCF \\
\hline Uric acid & Chain breaking (scavenging) & Water soluble & Plasma, saliva, GCF \\
\hline $\begin{array}{l}\text { Reduced glutathione (including } \\
\text { cysteine) }\end{array}$ & $\begin{array}{l}\text { Chain breaking (scavenging) } \\
\text { Substrate for enzyme GSH-Px }\end{array}$ & Water soluble & $\begin{array}{l}\text { Plasma, alveolar lining fluid of lungs, } \\
\text { ?saliva, ?GCF }\end{array}$ \\
\hline
\end{tabular}

$\mathrm{CSF}=$ cerebrospinal fluid.

at concentrations as low as $10-20 \mu \mathrm{M}$. Such disruptions include the inactivation of glucose and amino acid transport systems and the $\mathrm{K}^{+}$ ion pump. Cell lysis occurs at higher hypochlorous acid concentrations and hypochlorous acid is capable of oxidising $\alpha-1$-antitrypsin ${ }^{53}$ and is also reported to activate neutrophil collagenase. ${ }^{55}$ In the presence of amino acids hypochlorous acid reacts to form chloramines, which in turn protect cells from the former. ${ }^{33}$ Hypochlorous acid is removed by reaction with the scavenging antioxidants albumin and ascorbic acid. ${ }^{13}$

\section{SINGLET OXYGEN}

Singlet oxygen $\left({ }^{1} \mathrm{O}_{2}\right)$ is not a radical as it does not contain an unpaired electron. It is formed by an input of energy to $\mathrm{O}_{2}$, which results in the reversal of spin direction of one of the outermost unpaired electrons, from a parallel spin to an opposing spin direction. This renders the singlet oxygen molecule unstable and more capable of oxidising other molecules. It is highly reactive with membrane lipids to produce peroxides, but information about its role in tissue damage is limited, and its role in periodontal inflammation is unknown.

\section{Antioxidant mechanisms}

The body contains a number of protective antioxidant mechanisms, whose specific role is to remove harmful oxidants as they form, or to repair damage caused by ROS in vivo. Antioxidants may be regarded as those substances which when present at low concentrations, compared with those of an oxidisable substrate, will significantly delay or inhibit oxidation of that substrate. ${ }^{43}$

Antioxidants are classified according to their mode of action (table 1). Important antioxidants include: (1) the chain breaking or scavenging antioxidants: vitamin $\mathrm{E}$ ( $\alpha$-tocopherol), vitamin $C$ (ascorbic acid), vitamin $A$ ( $\beta$-carotene), urate, bilirubin, and those substances containing thiol groups; (2) preventative antioxidants: these function largely by sequestering transition metal ions and preventing Fenton reactions and are therefore largely proteins by nature (for example, albumin, transferrin, lactoferrin, caeruloplasmin, haptoglobin, and ascorbic acid); and (3) enzyme antioxidants: these are enzyme systems that function by catalysing the oxidation of other molecules (for example, SOD, catalase and glutathione peroxidase).

The amount of information available relating to the importance of the body's antioxidant systems in protecting against such damage is substantial ${ }^{1344}$ and yet only two studies ${ }^{5657}$ have investigated total antioxidant defence within biological fluids in relation to periodontal disease. Many antioxidants function by more than one mechanism. The enzyme based systems, including SOD, catalase and glutathione peroxidase have been mentioned previously and further review will be limited to those extracellular antioxidants of perceived importance in periodontal disease.

\section{CAROTENOIDS (VITAMIN A)}

Carotenoids, such as $\beta$-carotene, have long double bonds to attract and quench radical attack, ${ }^{58}$ but currently little is known about the interactions of carotenoids and reactive oxygen species. Vitamin A deficiency has been implicated in periodontal destruction with animal models but results have not been reproduced in humans.

It is unlikely that individual vitamin deficiencies have significant detrimental effects on the periodontium, but the combined effects of vitamins $A, C$ and $E$ have potential as therapeutic adjuncts in view of their powerful antioxidant activities.

\section{ASCORBIC ACID (VITAMIN C)}

Ascorbate protects against oxidants present in cigarette smoke ${ }^{41}$ and is a powerful scavenger of hypochlorous acid, superoxide, singlet oxygen, and hydroxyl radicals. It also possesses the ability to regenerate $\alpha$-tocopherol from the tocopherol radical that forms at membrane surfaces. GCF concentrations of ascorbic acid have been reported to be three times higher than those of plasma ${ }^{59}$ and it has been shown to prevent activation of neutrophil derived collagenase $^{55}$ in GCF. In rheumatoid arthritis ${ }^{60}$ plasma ascorbate concentrations are low but there is little evidence for any relation between plasma ascorbate concentrations and inflammatory periodontitis, ${ }^{61}$ though increased gingival bleeding is a common result of ascorbate depletion..$^{61-63}$ 
TOCOPHEROLS (VITAMIN E)

Alpha-tocopherol is located within cell membrane phospholipids and is a major chain breaking antioxidant ${ }^{64}$ but has limited mobility, which restricts its efficacy. ${ }^{65}$ However, many reactive oxygen species are generated in aqueous solution, particularly those from phagocytes and the vascular endothelium, and the role of $\alpha$-tocopherol in the pathogenesis of the periodontal diseases is thus likely to be a minor one. In one study ${ }^{66}$ no differences were detected in plasma vitamin $\mathrm{E}$ concentrations in patients with and without periodontal disease, and in another, ${ }^{67}$ its prostaglandin inhibitory properties were credited for reducing periodontal inflammation.

\section{URIC ACID}

Uric acid is a relatively powerful scavenging antioxidant of water soluble radicals, ${ }^{68}$ such as hypochlorous acid and singlet oxygen. It can also bind copper and iron ions and increased concentrations of uric acid breakdown products are reported in patients with rheumatoid arthritis. ${ }^{69}$ Reaction of uric acid with some radicals (for example, $\mathrm{OH}$ ) can produce uric acid radicals, but these are easily removed by ascorbate. ${ }^{70}$ It has recently been reported that uric acid is the major ( $>70 \%$ ) antioxidant in saliva ${ }^{56}$ and while it is also found in GCF, its antioxidant contribution to GCF has not been investigated.

\section{CYSTEINE AND REDUCED GLUTATHIONE}

Glutathione is an essential tripeptide with many important functions. In its reduced form (GSH) glutathione is an important antioxidant (radical scavenger), a property bestowed upon it by its central thiol containing cysteine amino acid. It is also regarded as a pivotal molecule to the immune system, ${ }^{71}$ especially for regulation of IL-2 dependent T-lymphocyte proliferation. ${ }^{72-74}$

The role of reduced glutathione (GSH) in the regulation of pro-inflammatory cytokines ${ }^{75}$ is of great potential importance in periodontal disease. There is evidence that increasing cytosolic cysteine (and thus GSH) concentrations of monocytes and macrophages (using a synthetic form of cysteine called $\mathrm{N}$-acetylcysteine) blocks hydrogen peroxide mediated activation of NF-KB (fig 5), and thus production of pro-inflammatory cytokines ${ }^{45}$ by this route. Cytokines, such as TNF $\alpha, \mathrm{IL}-1 \beta$ and IL-6, are associated with the activation of bone resorbing processes ${ }^{76-78}$ and IL-8 is reported to stimulate polymorphonuclear leucocyte activity. ${ }^{79}$ Normally, intracellular concentrations of GSH are high (0.1-10 mM), ${ }^{75}$ but extracellular fluid concentrations are low $(2 \mu \mathrm{M}$ in human plasma). ${ }^{13}$ However, local production of GSH has been reported in alveolar lining fluid at very high concentrations of $400 \mu \mathrm{M},{ }^{80}$ with concentrations being raised in smokers and deficient in patients with pulmonary fibrosis ${ }^{81}$ and acute respiratory distress syndrome. ${ }^{82}$

Certain putative periodontopathogens are capable of metabolising L-cysteine or degrading GSH to form hydrogen sulphide within the periodontal pocket. ${ }^{83-86}$ The formation of hydrogen sulphide within the periodontal pocket is toxic to mammalian cells by inactivating cytochrome oxidase ${ }^{87}$ and is also reported to inhibit catalase. ${ }^{88}$ It can be seen how the degradation of cysteine by oral microbiota may also prevent the inhibition of NF- $\mathrm{KB}$ mediated production of pro-inflammatory cytokines in the periodontal environment, thereby increasing the risk of cytokine related tissue damage.

THE CONCEPT OF TOTAL ANTIOXIDANT CAPACITY As ROS and antioxidant defence mechanisms seem to act in concert rather than alone, an example being the re-cycling of $\alpha$-tocopherol by vitamin $C$, studies of individual antioxidants in relation to inflammatory disease may not necessarily yield useful information. Research is now being directed towards assays for total antioxidant capacities of biological fluids, while not forgetting the importance of the constituent antioxidant compounds. Wayner et $a l^{89}$ have reported the measurement of total peroxyl radical trapping parameter (TRAP assay), which is sensitive to all known chain breaking antioxidants but is a complex and time consuming assay to perform. Our group has recently reported a rapid and simple enhanced chemiluminescence (ECL) assay ${ }^{50}$ for total antioxidant quantification in biological fluids including serum, saliva and GCF. Initial data have revealed a reduced salivary total antioxidant concentration in patients with periodontitis relative to those with periodontal health, with no differences in serum concentrations. Guarnieri et $a l^{91}$ investigated GCF superoxide scavenging capacity in 14 patients with adult periodontitis and 16 healthy controls. They found no difference between test and control groups. The differences in results may be explained by the fact that in this study GCF was collected by a crevice washing technique that involved 12 washings with a microsyringe and samples were centrifuged and stored at $-20^{\circ} \mathrm{C}$ prior to assay. It is likely that the repeated washing and centrifugation would have resulted in oxidation of several antioxidant components by the time of assay. Furthermore, data ${ }^{57}$ are available demonstrating that storage of fluid samples at $-20^{\circ} \mathrm{C}$ results in a loss of antioxidant activity with time, and that storage should be by immersion in liquid nitrogen to prevent oxidation.

A local antioxidant response found in GCF and also in saliva but not in serum, has been identified as a low molecular weight ( $<10$ kilodaltons) thiol, and this response has been reproduced from the cytosol of anaerobically stimulated neutrophils and mimicked using Lcysteine and cysteamine. ${ }^{92}$ It seems logical that polymorphonuclear leucocytes should contain powerful intracellular antioxidants in view of their high potential for radical generation. However, the discovery of high GSH concentrations within alveolar lining fluid ${ }^{80}$ and the detection of a low molecular weight thiol in $\mathrm{GCF}^{92}$ raises the possibility that the production of antioxidant thiols at vulnerable epithelial surfaces is an important defence mechanism 
against unwanted ROS mediated damage (whether polymorphonuclear leucocyte mediated or from exogenous sources) that is common to several organs. Considerable work is needed in this area to elucidate the true identity of the GCF antioxidant reported and to investigate the presence of similar thiol antioxidants at high concentrations in anatomical sites that are exposed to similar sources of potential damage, such as the cervical epithelium.

\section{Conclusions}

There are many similarities between the hostparasite interactions that characterise periodontitis and diseases affecting other areas of the body, such as inflammatory lung disease and rheumatoid arthritis. In the lungs and periodontal tissues, the external environment is separated from the internal connective tissues by a delicate epithelial barrier, behind which large scale polymorphonuclear leucocyte responses are seen in reaction to various bacterial activities. ${ }^{93}$ While the role of the polymorphonuclear leucocyte is primarily a protective one, host tissue damage can result indirectly from over exuberant polymorphonuclear leucocyte and monocyte responses as well as directly from the colonising pathogens themselves. Reactive oxygen species produced by inflammatory and immune cells have been associated with significant tissue damage. ${ }^{94}$ To combat such damage the body possesses a variety of antioxidant defence mechanisms, whose role is to protect vital cell and tissue components from radicals of host cell as well as parasitic origin. Study of local antioxidant systems is likely to yield valuable information about the pathogenesis of certain diseases, and such antioxidants should be studied when acting in concert as well as in individual systems.

The balance between antioxidant defence and repair systems, and pro-oxidant mechanisms of cell damage may be tipped in favour of tissue destruction either by increases in radical production or by a lowered antioxidant defence. While the former situation has been demonstrated in periodontitis, the latter has not, as the technology has not been available to measure total antioxidant defence in GCF until recently. Production of high concentrations of the antioxidant thiol, reduced glutathione (GSH), have been demonstrated in areas of the lung where delicate epithelial tissues are exposed to free radical attack. GSH, is dependent upon the amino acid cysteine for its antioxidant activity, for IL-2 dependent T-cell functions and also for other vital antiinflammatory mechanisms that rely upon preventing NF- $\kappa B$ translocation to defence cell nuclei. A local low molecular weight thiol has also been detected in GCF, which seems to contribute substantially to its overall antioxidant capacity. The kinetics of light recovery for this antioxidant, in the enhanced chemiluminescence assay used for its detection, can be reproduced by L-cysteine which may be of epithelial cell as well as polymorphonuclear leucocyte origin. Considerable work is needed to evaluate further local epithelial defence sys- tems, such that the important anti-inflammatory mechanisms, in addition to antioxidant activities of thiols such as reduced glutathione and cysteine, can be fully understood. If the GCF thiol is cysteine or GSH, these data together with those from alveolar lining fluid ${ }^{81}$ may lead to the development of new therapeutic pathways for inflammatory disease using cysteine and GSH preserving drugs such as $\mathrm{N}$-acetylcysteine, or indeed, other NF- $\kappa \mathrm{B}$ inhibitors.

I would like to express my sincere thanks to Dr J B Matthews for reading this manuscript and for his very helpful comments.

1 Todd JE, Lader D. 1988 Adult dental health survey of the United Kingdom. London: Office of Population Censuses and Surveys, Social Division 1988:131-44.

2 Löe $\mathrm{H}$, Theilade E, Jensen SB. Experimental gingivitis in man. F Periodontol 1965;35:177-87.

3 Chapple ILC. The initiation and progression of periodontal disease. In: Heasman PA, Millett DT, eds. The periodontal tissues and orthodontics in health and disease. Oxford: Oxford University Press, 1996:33-72.

4 Chapple ILC, Cross IA, Glenwright HD, Matthews JB. Calibration and reliability of the periotron 6000 for individual gingival crevicular fluid samples. 7 Periodontal Res 1995;30:73-9.

5 Charon JA, Mergenhagen SE, Gallin JI. Gingivitis and oral ulceration in patients with neutrophil destruction. $\mathcal{f}$ Oral Pathol 1985;14:150-5.

6 Delgado W, Calderon R. Acatalasia in two Peruvian siblings. f Oral Pathol 1979;8:358-68.

7 Cohen SG, Greenberg MS. Chronic oral herpes simplex virus infection in immunocompromised patients. Oral Surg Oral Med Oral Pathol 1985;59:465-71.

8 Asman B, Engstrom PE, Olsson T, Bergstrom K. Increased luminol enhanced chemiluminescence from peripheral granulocytes in juvenile periodontitis. Scand $\mathcal{F}$ Dental Res 1984;92:218-23.

9 Henry CA, Winfold TE, Laohapund P, Yotnuengnit P. Neutrophil chemiluminescence and opsonic activities of young people with periodontitis in Thailand. Arch Oral Biol 1984; 29:623-7.

10 Shapira L, Borinski R, Sela MN, Soskolne A. Superoxide formation and chemiluminescence of peripheral polymorphonuclear leukocytes in rapidly progressive periodontitis patients. $\mathcal{F}$ Clin Periodontol 1991;18:44-8.

11 Offenbacher S. Clinical trials of host modulation therapy. Proceedings of Joint Symposium on Clinical Trials Design and Analysis in Periodontics. National Institute of Health, Bethesda, Washington DC, USA. February 1996;1:37.

12 Halliwell B. Reactive oxygen species in living systems: source, biochemistry, and role in human disease. $\mathrm{Am} \mathcal{F}$ Med 1991;91 (Suppl 3C):3C14S-22S.

13 Halliwell B, Gutteridge JMC. The antioxidants of human extracellular fluids. Arch Biochem Biophys 1990;280:1-8.

14 Bartold PM, Wiebkin OW, Thonard JC. The effect of oxygen-derived free radicals on gingival proteoglycans and hyaluronic acid. $\mathcal{F}$ Periodontal Res 1984;19:390-400

15 Varani J, Fligiel SEG, Till GO, Kunkel RG, Ryan US, Ward PA. Pulmonary endothelial cell killing by human neutrophils: possible involvement of hydroxyl radical. $L a b$ Invest 1985;53:656-63.

16 Staal FJT, Roederer M, Herzenberg LA, Herzenberg LA. Intracellular thiols regulate activation of nuclear factor $\mathrm{KB}$ and transcription of human immunodeficiency virus. Proc Natl Acad Sci USA 1990;87:9943-7.

17 Pryor WA. Oxy-radicals and related species: their formation, lifetimes, and reactions. Annu Rev Physiol 1986;48:657-67.

18 Fridovich I. Superoxide dismutase: an adaptation to a paramangetic gas. F Biol Chem 1989;264:7761-4.

19 Imlay JA, Fridovich I. Assays of metabolic superoxide production in Escherichia coli. F Biol Chem 1991;266: 6957-65.

20 Crystal RG. Oxidants and respiratory tract epithelial injury: pathogenesis and strategies for therapeutic intervention. Am f Med 1991;91 (Suppl 3C):3C39S-44S

21 Curnette JT, Babior BM. Chronic granulomatous disease. Adv Hum Genet 1987;16:229-45.

22 Maly FE. The B-lymphocyte: a newly-recognised source of reactive oxygen species with immunoregulatory potential. Free Radic Res Commun 1990;8:143-8.

23 Key LL, Wolfe WC, Gundberg CM, Ries WL. Superoxide and bone resorption. Bone 1994;15:431-6.

24 McCord JM, Fridovich I. Superoxide dismutase an enzyme function for erythrocuprein (hemocuprein). $7 \mathrm{Biol}$ Chem 1969;244:6049-55.

25 Sutton HC, Winterbourn CC. On the participation of higher oxygenation states of iron and copper in Fenton higher oxygenation states of iron and copper

26 Stocks J, Gutteridge JMC, Sharpe RF, Dormandy TL. The inhibition of lipid autoxidation by human serum and its relationship to serum proteins and alpha tocopherol. Clin Sci 1974;47:223-33.

27 Gutteridge JMC, Patterson SK, Segal AW, Halliwell B. Inhibition of lipid peroxidation by the iron-binding protein lactoferrin. Biochem $\mathcal{F}$ 1981;199:259-61. 
28 Gutteridge JMC, Stocks J. Caeruloplasmin: physiological and pathological perspectives. CRC Crit Rev Clin Lab Sci and pathological per

29 Gutteridge JMC. Antioxidant properties of the proteins caeruloplasmin, albumin and transferrin. A study of their activity in serum and synovial fluid from patients with rheumatoid arthritis. Biochim Biophys Acta 1986;869:119-27.

30 Gutteridge JMC. The antioxidant activity of haptoglobin towards haemoglobin-stimulated lipid peroxidation. Biochim Biophys Acta 1987;917:219-23.

31 Esterbauer H, Zollner H, Schaur RJ. Hydroxyalkenals: cytotoxic products of lipid peroxidation. ISI Atlas Sci Biochem 1988;1:311-15.

32 Morrow JD, Hill KE, Burke RF, Nammour TM, Bads KF, Roberts LJ II. A series of prostaglandin $\mathrm{F}_{2}$-like compounds are produced in vivo in humans by a non-cyclooxygenase, free radical-catalysed mechanism. Proc Natl Acad Sci USA 1990;87:9383-7.

33 Morrow JD, Roberts LJ II. Quantification of noncyclooxygenase derived prostanoids as a marker of oxidative stress. Free Radic Biol Med 1991;10:195-200.

34 Pruijn FB, Bast A. Effects of free radicals on hormonally and non-hormonally regulated calcium homeostasis in rat liver microsomes and hepatocytes. Adv Biosci 1989;76:83-97.

35 Crompton M, Costi A, Hayat L. Evidence for the presence of reversible $\mathrm{Ca}^{2+}$ dependent pore activated by oxidative of reversible $\mathrm{Ca}^{2+}$ dependent pore activated by oxidative

36 Dean RT, Thomas SM,Garner A. Free-radical-mediated fragmentation of monoamine oxidase in the mitochondrial membrane. Role of lipid radicals. Biochem 1986;240:489-94

37 Cooper B, Creeth JM, Donald ASR. Studies of the limited degradation of mucous glycoproteins. The mechanism of peroxide reaction. Biochem f 1985;228:615-26.

38 Breimer LH. Repair of DNA damage induced by reactive oxygen species. Free Radic Res Commun 1991;14:159-71.

39 Jackson JH, Gajewski E, Schraufstatter IU, Hyslop PA Fuciarelli AE, Cochrane CG, Dizdaroglu M. Damage to
the bases in DNA induced by stimulated neutrophils. $\mathcal{F}$ Clin Invest 1988;84:1644-9.

40 Aruoma OL, Halliwell B, Dizdaroglu M. Iron-dependent modification of bases in DNA by the superoxide radical generating system hypoxanthine/xanthine oxidase. $\mathcal{F}$ Biol Chem 1989;264:13024-8.

41 Cochrane C. Cellular injury by oxidants. $\mathrm{Am} f \mathrm{Med}$ 1991;91(Suppl 3C):3C23S-30S

42 Halliwell B. How to characterise biological antioxidants. Free Radic Res Commun 1990;9:1-31.

43 Halliwell B, Gutteridge JMC. In: Free radicals in biology and medicine. 2nd edn. Oxford: Clarendon Press, 1989.

44 Halliwell B, Gutteridge JMC, Cross CE. Free radicals, antioxidants, and human disease: where are we now? f Lab Clin Med 1992;119:598-620.

45 Schreck R, Rieber P, Baeuerle A. Reactive oxygen intermediates as apparently widely-used messengers in the activation of the NF- $\kappa \mathrm{B}$ transcription factor and HIV-1. $E M B O$ f 1991;10:2247-58.

46 Baeurele PA, Baltimore D. Activation of DNA-binding activity in an apparently cytoplasmic precursor of the NF-KB transcription factor. Cell 1988;53:211-17.

47 Liberman TO, Baltimore D. Activation of interleukin-6 gene expression through NFKB transcription factor. Mol Cell Biol 1990;10:2327-34.

48 Osborn L, Kunkel S, Nabel G. Tumour necrosis factor $\alpha$ and interleukin 1 stimulate the human immunodeficiency virus enhancer by activation of nuclear factor $\mathrm{KB}$. Proc Natl Acad Sci USA 1989;86:2236-40.

49 Shirikawa F, Chedid M, Suttles J, Plooak PA, Mizel SB. Interleukin 1 and cyclic AMP induce $K$ immunoglobulin light-chain expression via NF- $\kappa$-like DNA-binding protein. Mol Cell Biol 1989;9:959-64.

50 Meichle A, Schutze S, Hanzel G, Brunsing D, Kronke M. Protein kinase $\mathrm{C}$-independent activation of nuclear factor kappa B by tumour necrosis factor. $\mathcal{F}$ Biol Chem 1990;265: 8339-43.

51 Vincenti MP, Burrell TA,Taffet SM. Regulation of NFאB activity in murine macrophages: effect of bacterial lipopolysaccharide and phorbol ester. F Cell Physiol 1992;150:204-13.

52 Gutteridge JMC. Biological origin of free radicals, and mechanisms of antioxidant protection. Chemico-Biological Interactions 1994;91:133-40.

53 Weiss SS. Tissue destruction by neutrophils. $N$ Engl f Med 1990;320:365-76.

54 Schraufstatter IU, Browne K, Harris A, Hyslop PA, Jackson $\mathrm{JH}$, Quehenberger $\mathrm{O}$, Cochrane $\mathrm{C}$. Mechanisms of hypochlorite $(\mathrm{HOCl})$ injury of target cells. $\mathcal{f}$ Clin Invest 1990;85:554-62.

55 Suomalainen K, Sorsa T, Lindy O, Saari H, Konttinen YT, Uitto VJ. Hypochlorous acid induced activation of human neutrophil and gingival crevicular fluid collagenase can be inhibited by ascorbate. Scand $\mathcal{F}$ Dental Res 1991;99:397-405.

56 Moore S, Calder KAC, Miller NJ, Rice-Evans A. Antioxidant activity of saliva and periodontal disease. Free Radic Res 1994;21:417-25.

57 Chapple ILC, Thorpe GHG, Mason GI, Matthews JB. Low molecular weight thiol antioxidant activity in oral fluids. In: Szalay A, Kricka P, eds. Bioluminescence and chemiluminescence. Chichester: John Wiley and Sons, 1997.

58 Krinsky NI. Antioxidant functions of carotenoids. Free Radic Biol Med 1989;7:617-35.

59 Meyle J, Kapitza K. Assay of ascorbic acid in human crevicular fluid from clinically healthy gingival sites by
high-performance liquid chromatography. Arch Oral Biol high-performance
60 Lunec J, Blake DR. The determination of dehydroascorbic acid and ascorbic acid in the serum and synovial fluid of patients with rheumatoid arthritis (RA). Free Radic Res Commun 1981;1:31-9.

61 Leggott PJ, Robertson PB, Jacob RA, Zambon JJ, Walsh M Armitage GC. Effects of ascorbic acid depletion and supplementation on periodontal health and subgingival microflora in humans. F Dental Res 1991;70:1531-6.

62 Jacob RA, Omaye ST, Skala JH, Leggott PJ, Rothman DL, Murray PA. Experimental vitamin C depletion and supplementation in young men. Nutrient interactions and

63 Vaananen MK, Markkanen HA, Tuovinen VJ, Kullaa AM Karinpaa AM, Kumpusalo EA. Periodontal health related to plasma ascorbic acid. Proc Finnish Dental Soc 1993;89:51-9.

64 Esterbauer H, Striegl G, Puhl H, Oberreither S, Rothenede $M$, El-Saadani $M$, Jürgens $G$. The role of vitamin $E$ and carotenoids in preventing oxidation of low density lipoproteins. Ann NY Acad Sci 1989;570:254-67.

65 Niki E. Lipid antioxidants: how they may act in biological systems. Br 7 Cancer 1987;55:157-7.

66 Slade EW Jr, Bartuska D, Rose LF, Cohen DW. Vitamin E and periodontal disease. $\mathcal{F}$ Periodontol 1976;47:352-4.

67 Cerna H, Fiala B, Fingerova H, Pohanka E, Szwarcon A Contribution to indication of total therapy with vitamin $\mathrm{E}$ in chronic periodontal disease (pilot study). Acta Universitatis Palackianae Olomucensis Facultatis Medicae 1984;107 $167-70$

68 Ames BN, Cathcart R, Schwiers E, Hochstein P. Uric acid provides an antioxidant defence in humans against oxidantand radical-caused ageing and cancer: a hypothesis. Proc Natl Acad Sci USA 1981;78:6858-62.

69 Grootveld M, Halliwell B. Measurement of allantoin and uric acid in human body fluids. A potential index of free-radicals in vivo? Biochem 7 1987;243:803-8.

70 Aruoma OL, Halliwell B, Dizdaroglu $M$. Iron irondependent modification of bases in DNA by the superoxide radical generating system hypoxanthine/xanthine oxidase. $f$ Biol Chem 1989;264:13024-8.

71 Fanger MW, Hart DA, Wells JV, Nisonoff A. Enhancement by reducing agents of the transformation of human and rabbit peripheral lymphocytes. f Immunol 1970; 105:1043-5.

72 Dröge W, Eck HP, Näher H, Pekar U, Daniel V. Abnormal amino acid concentrations in the blood of patients with acquired immunodeficiency syndrome (AIDS) may contribute to the immunological defect. Biological Chemistry Hoppe-Seyler 1988;369:143-8

73 Liang GM, Lee N, Cattell D, Liang SM. Glutathione regulates interleukin-2 activity on cytotoxic T-cells. F Biol Chem 1989;264:13519-23.

74 Suthanthiran M, Anderson ME, Sharma VK, Meister A Glutathione regulates activation-dependent DNA synthesis in highly purified normal human $T$ lymphocytes stimulated by the CD2 and CD3 antigens. Proc Natl Acad Sci USA by the CD2 and

75 Morris PE, Bernard GR. Significance of glutathione in lung disease and implications for therapy. $\mathrm{Am} \mathcal{F} \mathrm{Med} S \mathrm{~S}$ 1994;307:119-27.

76 Bertolini DR, Nedwin GE, Bringman TS, Smith DD, Mundy GR. Stimulation of bone resorption and inhibition of bone formation in vitro by human tumour necrosis factor. Nature 1986;319:516-18.

77 Amano S, Hanazawa S, Hirose K, Ohmori Y, Kitano S. Stimulatory effect on bone resorption by interleukin-1-like cytokine produced by an osteoblast-rich population of mouse calvarial cells. Calific Tissue Int 1988;43:88-91.

78 Littlewood A, Aarden L, Evans D, Russell R, Gowen M. Human osteoblast-like cells to not respond to interleukin-6. f Bone Miner Res 1991;6:141-8.

79 Schroeder J-M, Mrowietz U, Morita E, Christophers E. Purification and partial biochemical characterisation of a human monocyte-derived, neutrophil activating peptide that lacks interleukin-1 activity. I Immunol 1987; 139:3474-83.

80 Bernard GR. N-acetylcysteine in experimental and clinical acute lung injury. Am f Med 1991;91 (Suppl 3C):54S-59S

81 Cantin A, North SL, Hubbard RC, Crystal RG. Normal alveolar epithelial lining fluid contains high levels of glutathione. $\mathcal{F}$ Appl Physiol 1987;63:152-7.

82 Pacht ER, Timerman AP, Lykens MG, Merola AJ. Deficiency of alveolar fluid glutathione in patients with 1991;100:1397-403.

83 Persson S, Edlund M-B, Claesson R, Carlsson J. The formation of hydrogen sulfide and methyl mercaptan by oral bacteria. Oral Microbiol Immunol 1990;5:195-201

84 van der Hoeven JS, van den Kieboom CWA, Schaeken MJM. Sulfate-reducing bacteria in the periodontal pocket. Oral Microbiol Immunol 1995;10:288-90.

85 Carlsson J, Larsen JT, Edlund E-D. Peptostreptococcus micros has a uniquely high capacity to form hydrogen sulfide from glutathione. Oral Microbiol Immunol 1993;8:42-5.

86 Carlsson J, Larsen JT, Edlund, E-D. Utilization of glutathione (L- $\gamma$-glutamyl-L-cysteinylglycine) by Fusobacterium nucleatum subspecies nucleatum. Oral Microbio Immunol 1994;9:297-300.

87 Nicholls P, Kim KJ. Sulfide as an inhibitor and electron donor for the cytochrome c oxidase system. Can $\mathcal{F}$ Biochem 1982;60:613-23.

88 Claesson R, Granlund-Edstedt M, Persson S, Carlsson J. Activity of polymorphonuclear leukocytes in the presence of sulfide. Infect Immun 1989;57:2776-81. 
89 Wayner DD, Burton GW, Ingold KU, Barclay LR, Locke SJ. The relative contributions of vitamin $\mathrm{E}$, urate, ascorbate and proteins to the total peroxyl radical-trapping antioxidant activity of human blood plasma. Biochim Biophys Acta dant activity of hum

90 Whitehead TP, Thorpe GHG, Maxwell SRJ. Enhanced chemiluminescent assay for antioxidant capacity in biological fluids. Anal Chim Acta 1992;266:265-77.

91 Guarnieri C, Zucchelli G, Bernardi F, Scheda M, Valentini $\mathrm{AF}$, Calandriello M. Enhanced superoxide production with no change of the antioxidant activity in gingival fluid of patients with adult periodontitis. Free Rad Res Commun 1991;15:11-16.

92 Chapple I, Eftimiadi C, Dibart S, Socransky S, Matthews J. Low molecular weight antioxidant activity in gingival crevicular fluid (GCF). F Dental Res 1996;75:49.

93 Marucha PT, Zeff RA, Kreutzer DL. Regulation of IL-1 $\beta$ gene expression in human peripheral blood PMN. $\mathcal{F}$

94 Page RC, Schroeder HE. Pathogenesis of inflammatory periodontal disaese-a summary of current work. Lab Invest 1976;34:235-48. 